CLINICAL STUDY

\title{
Vitamin D-associated polymorphisms are related to insulin resistance and vitamin $D$ deficiency in polycystic ovary syndrome
}

\author{
Elisabeth Wehr, Olivia Trummer, Albrecht Giuliani ${ }^{1}$, Hans-Jürgen Gruber ${ }^{2}$, Thomas R Pieber
} and Barbara Obermayer-Pietsch

Division of Endocrinology and Metabolism, Department of Internal Medicine, Medical University of Graz, Auenbruggerplatz 15, 8036 Graz, Austria, ${ }^{1}$ Department of Obstretrics and Gynecology, Medical University of Graz, Auenbruggerplatz 14, 8036 Graz, Austria and ${ }^{2}$ Clinical Institute of Medical and Chemical Laboratory Diagnostics, Medical University of Graz, Auenbruggerplatz 15, 8036 Graz, Austria

(Correspondence should be addressed to E Wehr; Email: elisabeth.wehr@medunigraz.at)

\begin{abstract}
Introduction: Women with polycystic ovary syndrome (PCOS) frequently suffer from metabolic disturbances including insulin resistance (IR), which might be related to vitamin D metabolism. We aimed to investigate the association of polymorphisms in the vitamin D receptor (VDR) gene as well as vitamin D level-associated genes with metabolic and endocrine parameters in PCOS women. Moreover, we examined whether there are associations with PCOS susceptibility.

Methods: Metabolic, endocrine, and anthropometric measurements and oral glucose tolerance tests were performed in 545 PCOS and 145 control women. Genotyping of VDR (Cdx2, Bsm-I, Fok-I, Apa-I, and Taq-I), GC, DHCR7, and CYP2R1 polymorphisms was performed.

Results: 25-Hydroxyvitamin D (25(OH)D) levels showed significant negative correlation with IR and positive correlation with insulin sensitivity $(P<0.05$ for all) in PCOS women. In PCOS women, the VDR $C d x 2$ 'AA' genotype was associated with lower fasting insulin $(P=0.039)$ and homeostatic model assessment-IR $(P=0.041)$ and higher quantitative insulin-sensitivity check index $(P=0.012)$ and MATSUDA index $(P=0.003)$. The VDR Apa-I 'AA' genotype was associated with lower testosterone $(P=0.028)$ levels. In PCOS women, 170 women (31.2\%) presented with $25(\mathrm{OH}) \mathrm{D}$ levels $<20 \mathrm{ng} / \mathrm{ml}$. PCOS women carrying the GC 'GG' genotype and the DHCR7 'GG' genotype had a significantly higher risk for $25(\mathrm{OH}) \mathrm{D}$ levels $<20 \mathrm{ng} / \mathrm{ml}$ (OR 2.53 (1.27-5.06), $P=0.009$, and OR 2.66 (1.08-6.55), $P=0.033$ respectively) compared with PCOS women carrying the GC 'TT' genotype and DHCR 'TT' genotype in multivariate analyses. We observed no association of genetic variations and PCOS susceptibility. Conclusion: VDR and vitamin D level-related variants are associated with metabolic and endocrine parameters including 25(OH)D levels in PCOS women.
\end{abstract}

European Journal of Endocrinology 164 741-749

\section{Introduction}

Polycystic ovary syndrome (PCOS) is the most common female endocrine disorder with a prevalence of $~ 5-10 \%$ in women of reproductive age (1-3); the incidence, however, might increase due to nutritional changes. PCOS is characterized by increased ovarian and adrenal androgen secretion; hyperandrogenic symptoms such as hirsutism, acne, and/or alopecia; menstrual irregularity; and polycystic ovaries. In addition, insulin resistance (IR) is common in PCOS women (4), who are therefore at an increased risk of type 2 diabetes (5).

Accumulating evidence suggests that vitamin D deficiency might be a causal factor in the pathogenesis of IR and the metabolic syndrome in PCOS $(6,7)$. The results from our study in PCOS women investigating the effect of vitamin D supplementation indicate a favorable effect of vitamin D supplementation on glucose metabolism (8). This notion is supported by the fact that the vitamin $\mathrm{D}$ receptor (VDR) regulates more than $3 \%$ of the human genome, including genes that are crucial for glucose metabolism $(9,10)$. However, data on the role of gene variants involved in vitamin D metabolism in PCOS are sparse. PCOS status has been shown to be associated with the VDR Apa-I and Fok-I polymorphism was associated with IR in a cohort including 162 PCOS women (11). By contrast, a small study including 56 PCOS women reported an association of VDR Bsm-I variants with sex hormone binding globulin (SHBG) levels in PCOS women, whereas no association was found between VDR polymorphisms and metabolic parameters (12). Recently, the results from a genome-wide association study of 25-hydroxyvitamin D (25(OH)D) levels in 33996 individuals of 
European descent from 15 cohorts established a role for common genetic variants in the regulation of $25(\mathrm{OH}) \mathrm{D}$ levels (13). Variants near genes involved in cholesterol synthesis (DHCR7), hydroxylation (CYP2R1), and vitamin D transport (GC) affect vitamin D status. So far, the role of those polymorphisms in PCOS has not been investigated.

The aim of this study was to investigate the association of VDR variants including $C d x 2, B s m-I$, Fok-I, Apa-I, and Taq-I as well as GC, DHCR7, and CYP2R1 variants with metabolic and endocrine parameters including $25(\mathrm{OH}) \mathrm{D}$ levels in a cohort of PCOS women. Moreover, we examined whether there are associations with PCOS susceptibility.

\section{Methods}

\section{Subjects}

The study cohort consisted of 545 women with PCOS aged 16-45 years, who were routinely referred to our outpatient clinic for PCOS evaluation from 2006 to 2010. Totally, 145 body mass index (BMI)-matched women within the same age range, who were referred for routine thyroid evaluation to our outpatient clinic from 2009 to 2010, were invited to participate in the trial as a control group. All the control women had normal thyroid function, regular menstrual cycles, normal serum androgens, and no clinical signs of hyperandrogenism.

\section{PCOS women}

PCOS was diagnosed using the Rotterdam criteria (14). Of the following three criteria, two are required to confirm the diagnosis: clinical and/or biochemical signs of hyperandrogenism, oligo- and/or anovulation, and polycystic ovaries (by ultrasound). Hyperandrogenism was defined by the clinical presence of hirsutism (Ferriman-Gallwey score $\geq 6$ ), acne, or alopecia and/or elevated androgen levels (testosterone normal range $<0.77 \mathrm{ng} / \mathrm{ml}$ and free testosterone normal range $<3.18 \mathrm{pg} / \mathrm{ml}$ ). Oligo- and/or anovulation were defined by the presence of oligomenorrhea or amenorrhea. Polycystic ovarian morphology was examined by ultrasound (14). Hyperprolactinemia, Cushing's syndrome, congenital adrenal hyperplasia, and androgen secreting tumors were excluded by specific laboratory analysis (cortisol, ACTH, $17 \alpha(\mathrm{OH})-$ progesterone, and DHEAS). PCOS women and control women did not take any medication known to affect endocrine parameters, carbohydrate metabolism, or serum lipid profile for at least 3 months before entering the study. The study protocol was approved by the local ethics committee, and written informed consent was obtained from each patient.

\section{Procedures}

Standard anthropometric data (height, weight, waist circumference (WC), hip circumference, and blood pressure) were obtained from each subject. WC was measured in a standing position midway between the lower costal margin and the iliac crest. Hip circumference was measured in a standing position at the maximum circumference over the buttocks. The BMI was calculated as the weight in kilograms divided by the square of height in meters. Hirsutism was quantified with the modified Ferriman-Gallwey score. Moreover, basal blood samples for hormonal (total testosterone, free testosterone, SHBG, androstenedione, DHEAS, free tri-iodothyronine, free thyroxine, TSH, $17 \alpha(\mathrm{OH})$-progesterone, and cortisol) and metabolic (glucose, insulin, total cholesterol (TC), high-density lipoprotein (HDL) cholesterol, low-density lipoprotein cholesterol, and triglycerides (TG)) determinations were collected at 0800-0900 h after overnight fast. All participants underwent a fasting $75 \mathrm{~g}$ oral glucose tolerance test. Blood samples were drawn after 30, 60, and $120 \mathrm{~min}$ for glucose and insulin determination. IR was estimated using the homeostatic model assessment-IR (HOMA-IR). HOMA-IR was calculated as the product of the fasting plasma insulin value $(\mu \mathrm{U} / \mathrm{ml})$ and the fasting plasma glucose value (mg/dl) divided by 405 (15). Quantitative insulin-sensitivity check index (QUICKI) was used to estimate insulin sensitivity. QUICKI was calculated as $1 / \log$ fasting insulin $(\mu \mathrm{U} / \mathrm{ml})+\log$ fasting glucose $(\mathrm{mg} / \mathrm{dl})$ (16). To assess $\beta$-cell function, HOMA- $\beta$ was calculated as $(20 \times$ fasting insulin $(\mu \mathrm{U} / \mathrm{ml})) /($ fasting glucose $(\mathrm{mmol} / \mathrm{l})-3.5)$. MATSUDA index was calculated as $10000 / \sqrt{ }(($ fasting glucose $\times$ fasting insulin $) \times$ $\left(\right.$ mean glucose OGTT $\times$ mean insulin $\left._{\text {OGTT }}\right)$ ) (17). The free androgen index (FAI) was calculated as testosterone $(\mathrm{nmol} / \mathrm{l}) /$ SHBG $(\mathrm{nmol} / \mathrm{l}) \times 100$.

\section{Genotyping}

Blood samples were collected in tubes containing EDTA as anticoagulant. DNA was extracted using the NucleoSpin Blood method. Genotyping of VDR $C d x 2$ (rs11568820), Bsm-I (rs1544410), Fok-I (rs2228570), Apa-I (rs7975232), and Taq-I (rs731236) as well as GC (rs2282679), DHCR7 (rs12785878), and CYP2R1 (rs10741657) were performed by predesigned SNP Genotyping Assay (Applied Biosystems, Carlsbad, CA, USA).

\section{Biochemical analysis}

$25(\mathrm{OH}) \mathrm{D}$ was measured using a commercially available enzyme immunoassay (IDS, Boldon, UK) with intra- and interassay coefficients of variation (CV) of 5.6 and $6.4 \%$ respectively. Insulin was measured by ELISA (Siemens, Erlangen, Germany) with intra- and interassay CV of 4.0 and 2.6 and 5.1 and $8.4 \%$ respectively. Free testosterone was determined using an RIA (DSL, Webster, 
TX, USA). SHBG, PTH (Roche), and total testosterone (Siemens, Erlangen, Germany) were measured by luminescence immunoassay. Androstenedione was determined using ELISA (Biotec, Suffolk, UK).

\section{Statistical analysis}

Data are presented as median (interquartile range) unless stated. The Kolmogorov-Smirnov test and descriptive statistics were used to evaluate the distribution of data. All continuous parameters following a non-normal distribution were logarithmically transformed when parametric tests were performed. After transformation, all parameters showed a normal distribution. Hardy-Weinberg equilibrium was tested by a $\chi^{2}$ goodness-of-fit test. Within the group of PCOS women, $\mathrm{AN}(\mathrm{C}) \mathrm{OVA}$ with post hoc analyses (Bonferroni) was used to compare continuous parameters between genotypes. We performed adjustment for age, BMI, 25(OH)D, month of blood sampling, and calcium levels, as appropriate. Nominal variables were analyzed using the $\chi^{2}$ and the Fisher exact tests. Binary logistic regression analyses were performed to examine the associations of hypovitaminosis D (dependent variable) with genotype, age, BMI, and month of blood sampling. We calculated two binary logistic regression analyses using two different thresholds for hypovitaminosis D: $25(\mathrm{OH}) \mathrm{D}$ levels $<20 \mathrm{ng} / \mathrm{ml}$ (vitamin D deficiency) and $25(\mathrm{OH}) \mathrm{D}$ levels $<30 \mathrm{ng} / \mathrm{ml}$ (combined vitamin D insufficiency and deficiency).

A $P$ value $<0.05$ was considered significant. Statistical analysis was performed using SPSS version 18.0 (SPSS, Inc., Chicago, IL, USA).

\section{Results}

Table 1 shows clinical and biochemical characteristics of PCOS and control women. PCOS women were significantly younger, had higher fasting insulin levels, HOMA-IR, HOMA- $\beta$, testosterone, and androstenedione levels, and significantly lower 25(OH)D, QUICKI, MATSUDA, and SHBG levels.

Median Ferriman-Gallwey score of PCOS women was 7 (2-11), and $52 \%$ of PCOS women were hirsute. Oligoor amenorrhea was present in 475 out of 545 PCOS women $(87 \%)$, and polycystic ovaries were found in 264 women $(48 \%)$.

In PCOS women, 170 women $(31.2 \%)$ presented with vitamin D deficiency $(<20 \mathrm{ng} / \mathrm{ml}), 189$ women (34.7\%) had vitamin D insufficiency $(20-29.9 \mathrm{ng} / \mathrm{ml})$, and 186 women $(34.1 \%)$ had a sufficient vitamin D status. In control women, vitamin D deficiency and vitamin D insufficiency were less common $(P<0.001)$. Among the control women, 25 women $(17.2 \%)$ presented with vitamin D deficiency $(<20 \mathrm{ng} / \mathrm{ml})$, 38 women $(26.2 \%)$ had vitamin D insufficiency $(20-29.9 \mathrm{ng} / \mathrm{ml})$, and 82 women $(56.6 \%)$ had a sufficient vitamin D status.

\section{Genotyping}

There was no significant difference in genotype frequencies between PCOS and control women. In detail, distribution of the VDR $C d x 2$ genotype was $64 \%(n=346) \mathrm{GG}, 32 \%(n=176) \mathrm{GA}$, and $4 \%(n=23)$ AA in PCOS women and $66 \%(n=96) \mathrm{GG}, 32 \%(n=46)$ GA, and $2 \%(n=3)$ AA in control women $(P=0.420)$.

Table 1 Baseline characteristics (median (interquartile range)) of PCOS and control women. To convert 25(OH)D levels into nM/l, multiply by 2.496 .

\begin{tabular}{lccr}
\hline & $\begin{array}{c}\text { PCOS women } \\
(n=545)\end{array}$ & $\begin{array}{c}\text { Control women } \\
(n=145)\end{array}$ & $\boldsymbol{P}$ value \\
\hline Age (years) & $27(23-31)$ & $29(26-36)$ & $<0.001$ \\
BMl (kg/m $\left.{ }^{2}\right)$ & $24.2(21.2-29.0)$ & $24.4(20.9-29.2)$ & 0.845 \\
WHR & $0.79(0.74-0.86)$ & $0.81(0.76-0.86)$ & 0.234 \\
Fasting glucose $(\mathrm{mg} / \mathrm{dl})$ & $86(80-92)$ & $88(82-91)$ & 0.753 \\
Glucose 2 $\mathrm{h}(\mathrm{mg} / \mathrm{dl})$ & $98(84-119)$ & $93(78-112)$ & 0.121 \\
AUCgluc & $176.8(154.8-202.0)$ & $167.5(146.5-194.8)$ & 0.090 \\
HbA1c $(\%)$ & $5.1(5.0-5.3)$ & $5.2(5.0-5.4)$ & 0.794 \\
Fasting insulin $(\mu \mathrm{U} / \mathrm{ml})$ & $6.3(4.0-10.5)$ & $4.9(3.0-7.8)$ & $<0.001$ \\
Insulin 2 h $(\mu \mathrm{U} / \mathrm{ml})$ & $34.0(20.4-58.0)$ & $32.5(17.8-57.2)$ & 0.133 \\
AUCins & $61.3(37.9-90.6)$ & $57.7(37.3-87.9)$ & 0.338 \\
HOMA-IR & $1.35(0.82-2.3)$ & $1.16(0.64-1.74)$ & 0.009 \\
HOMA- $\beta$ & $105.6(68.7-174.6)$ & $72.2(45.9-119.8)$ & 0.003 \\
QUICKI & $0.37(0.33-0.40)$ & $0.37(0.35-0.41)$ & 0.005 \\
MATSUDA & $7.88(4.8-12.5)$ & $8.03(4.64-13.67)$ & 0.006 \\
25(OH)D $(\mathrm{ng} / \mathrm{ml})$ & $25.7(18.3-34.8)$ & $32.0(22.9-40.5)$ & 0.002 \\
PTH $(\mathrm{pg} / \mathrm{ml})$ & $35.3(28.0-45.8)$ & $34.1(26.5-42.8)$ & 0.632 \\
Testosterone $(\mathrm{ng} / \mathrm{ml})$ & $0.63(0.48-0.80)$ & $0.44(0.32-0.57)$ & 0.001 \\
SHBG $(\mathrm{nmol} / \mathrm{l})$ & $44.8(29.8-61.5)$ & $76.4(51.6-200)$ & 0.003 \\
Free testosterone $(\mathrm{pg} / \mathrm{ml})$ & $2.60(1.98-3.47)$ & $1.71(1.18-2.03)$ & $<0.001$ \\
Androstenedione $(\mathrm{ng} / \mathrm{ml})$ & $2.8(2.0-4.2)$ & $1.5(1.0-2.5)$ & $<0.001$ \\
\hline
\end{tabular}


The allelic frequency of VDR Fok-I genotype was 15\% $(n=82) \mathrm{AA}, 45 \%(n=241) \mathrm{AG}$, and $40 \%(n=215) \mathrm{GG}$ in PCOS women and 16\% $(n=22)$ AA, $45 \%(n=60)$ AG, and $39 \% \quad(n=53)$ GG in control women $(P=0.954)$. The distribution of the VDR Bsm-I genotype was $40 \%(n=216) \mathrm{GG}, 45 \%(n=244) \mathrm{GA}$, and $15 \%$ $(n=77)$ AA in PCOS women and $36 \%(n=49)$ GG, $48 \%$ $(n=66) \mathrm{GA}$, and $16 \%(n=22) \mathrm{AA}$ in control women $(P=0.622)$. The allelic frequency of VDR Apa-I genotype was $26 \%(n=142) \mathrm{AA}, 51 \%(n=274) \mathrm{AC}$, and 23\% $(n=127)$ CC in PCOS women and 33\% $(n=48) \mathrm{AA}, 41 \%(n=60) \mathrm{AC}$, and $26 \%(n=37) \mathrm{CC}$ in control women $(P=0.155)$. The distribution of the VDR Taq-I genotype was $42 \%(n=226)$ TT, $44 \%(n=238)$ $\mathrm{TC}$, and $14 \%(n=72) \mathrm{CC}$ in PCOS women and $36 \%$ $(n=49)$ TT, $47 \%(n=65) \mathrm{TC}$, and $17 \%(n=23) \mathrm{CC}$ in control women $(P=0.335)$. The allelic frequency of GC genotype was $50 \%(n=221) \mathrm{TT}, 38 \%(n=172) \mathrm{TG}$, and $12 \%(n=55)$ GG in PCOS women and 46\% $(n=67) \mathrm{TT}$, $42 \%(n=61)$ TG, and $12 \%(n=17)$ GG in control women $(P=0.836)$. The distribution of the DHCR7 genotype was $51 \%(n=227) \mathrm{TT}, 41 \%(n=185) \mathrm{TG}$, and $8 \%(n=35)$ GG in PCOS women and 53\% $(n=77)$ TT, $36 \%(n=52) \mathrm{TG}$, and $11 \%(n=16)$ GG in control women $(P=0.440)$. The distribution of the CYP2R1 genotype was $38 \%(n=172) \mathrm{GG}, 47 \%(n=212) \mathrm{GA}$, and $15 \%(n=66)$ AA in PCOS women and $44 \%(n=64)$ GG, 36\% $(n=52)$ GA, and $20 \%(n=29)$ AA in control women $(P=0.121)$. None of the genotype frequency distributions deviated significantly from the HardyWeinberg equilibrium $(P>0.05)$.

\section{VDR Cdx2}

PCOS women with the AA genotype had significantly lower fasting insulin, HOMA-IR, and significantly higher QUICKI and MATSUDA levels than women with the GG or GA genotype. Moreover, there was a trend toward lower AUCins and HOMA- $\beta$ levels in PCOS women carrying the AA genotype (Table 2).

Table 2 Metabolic parameters (median (interquartile range)) according to VDR Cdx-2, GC and DHCR7 genotypes. To convert 25(OH)D levels into $\mathrm{nM} / \mathrm{l}$, multiply by 2.496 .

\begin{tabular}{|c|c|c|c|c|c|}
\hline & & Values & & $P$ value & $P$ value ${ }^{a}$ \\
\hline \multicolumn{6}{|l|}{ VDR $C d x-2$} \\
\hline Genotypes & $\mathrm{GG}$ & GA & $\mathrm{AA}$ & & \\
\hline AUCins & $64.7(40.8-88.8)$ & 57.4 (36.8-95.6) & $38.8(28.9-72.2)$ & 0.061 & 0.251 \\
\hline HOMA-IR & $1.37(0.86-2.55)$ & $1.27(0.65-2.1)$ & $1.09(0.55-1.75)$ & $0.041^{\mathrm{b}}$ & 0.052 \\
\hline НОМА- $\beta$ & $108.3(64.5-174.6)$ & $100.6(73.8-173.8)$ & $70.1(57.0-120.3)$ & 0.063 & 0.061 \\
\hline QUICKI & $0.36(0.33-0.39)$ & $0.37(0.34-0.41)$ & $0.38(0.35-0.43)$ & $0.014^{b}$ & $0.031^{b}$ \\
\hline MATSUDA & $7.79(4.71-11.0)$ & $7.85(4.9-14.1)$ & $10.59(6.24-19.7)$ & $0.003^{b}$ & $0.015^{\mathrm{b}}$ \\
\hline \multicolumn{6}{|l|}{$G C$} \\
\hline Genotypes & TT & TG & $\mathrm{GG}$ & & \\
\hline Weight (kg) & $65(57-78)$ & $70(60-83)$ & $68(58-81)$ & $0.008^{c}$ & $0.023^{c}$ \\
\hline Height (cm) & $165(162-170)$ & $168(163-171)$ & $165(161-170)$ & $0.027^{c}$ & $0.021^{c}$ \\
\hline BMI $\left(\mathrm{kg} / \mathrm{m}^{2}\right)$ & $23.3(20.7-28.0)$ & $25.3(21.6-29.9)$ & $24.6(20.8-30.9)$ & $0.049^{c}$ & $0.056^{d}$ \\
\hline WC $(\mathrm{cm})$ & $79(72-90)$ & $81(73-96)$ & $83(74-101)$ & $0.047^{e}$ & $0.030^{\mathrm{d}, \mathrm{e}}$ \\
\hline $\mathrm{HC}(\mathrm{cm})^{\prime}$ & $103(95-111)$ & $105(99-114)$ & $106(96-115)$ & 0.094 & NA \\
\hline HDL (mg/dl) & $67(56-79)$ & $60(51-76)$ & $68(62-76)$ & $0.005^{\mathrm{c}, \mathrm{f}}$ & $0.030^{c, f}$ \\
\hline QChol/HDL & $2.70(2.10-3.50)$ & $2.80(2.35-3.4)$ & $2.50(2.10-3.00)$ & $0.017^{f}$ & $0.011^{f}$ \\
\hline AUCins & $56.8(35.9-88.5)$ & $65.3(47.9-100.6)$ & $48.6(36.9-36.9)$ & $0.048^{f}$ & $0.380^{f}$ \\
\hline \multicolumn{6}{|l|}{ DHCR7 } \\
\hline Genotypes & TT & TG & $\mathrm{GG}$ & & \\
\hline $\mathrm{BMI}\left(\mathrm{kg} / \mathrm{m}^{2}\right)$ & $23.80(20.55-27.7)$ & $24.77(21.88-30.11)$ & $23.71(20.96-28.2)$ & 0.073 & NA \\
\hline $\mathrm{HC}(\mathrm{cm})$ & $102(96-110)$ & $105(99-116)$ & $103(96-112)$ & $0.025^{c}$ & 0.071 \\
\hline Fasting glucose (mg/dl) & $85(79-90)$ & $88(82-94)$ & $87(81-90)$ & $0.036^{c}$ & 0.439 \\
\hline Glucose 2 h (mg/dl) & $94(81-108)$ & 103 (88-122) & $100(86-123)$ & $0.010^{c}$ & 0.057 \\
\hline Fasting insulin $(\mu \mathrm{U} / \mathrm{ml})$ & $6.0(3.4-9.3)$ & $7.0(4.6-12.5)$ & $6.0(5.0-10.7)$ & $0.027^{c}$ & 0.305 \\
\hline Insulin $2 \mathrm{~h}(\mu \mathrm{U} / \mathrm{ml})$ & $28.5(19.0-56.6)$ & $38.8(24.0-65.4)$ & $47.0(29.3-67.1)$ & $0.006^{c}$ & $0.049^{c}$ \\
\hline HOMA-IR & 1.23 (0.73-1.95) & $1.62(0.93-2.81)$ & $1.46(1.05-2.38)$ & $0.020^{c}$ & 0.195 \\
\hline MATSUDA & 9.09 (5.80-13.77) & $6.91(4.00-10.38)$ & $6.71(4.43-12.3)$ & $0.006^{c}$ & 0.241 \\
\hline QUICKI & $0.37(0.35-0.40)$ & $0.36(0.33-0.39)$ & $0.36(0.34-0.38)$ & $0.039^{c}$ & 0.234 \\
\hline Phosphate (mmol/l) & 1.09 (0.94-1.19) & 1.03 (0.89-1.14) & $1.05(0.96-1.17)$ & $0.022^{c}$ & 0.085 \\
\hline TC (mg/dl) & 178 (159-202) & 177 (154-199) & 174 (155-201) & $0.029^{e}$ & $0.018^{e}$ \\
\hline
\end{tabular}

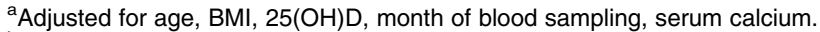

${ }^{b}$ Significant for GG vs AA.

CTT vs TG.

dAdjusted for age, $25(\mathrm{OH}) \mathrm{D}$, month of blood sampling, serum calcium.

'TT vs GG.

fTG vs GG. 
In multivariate-adjusted analyses, the results remained materially unchanged for fasting insulin, QUICKI, and MATSUDA but were attenuated for HOMA-IR.

We did not observe an association of $C d x 2$ polymorphism with endocrine parameters or 25(OH)D levels.

\section{VDR Apa-I}

In PCOS women, the androgen levels were different according to VDR Apa-I genotypes. In detail, the testosterone $(P=0.028)$ and androstenedione $(P=0.062)$ levels were higher in women carrying the $A A$ allele compared with PCOS women with the CC genotype (0.69 (0.51-0.82) ng/ml versus 0.59 $(0.46-0.75) \mathrm{ng} / \mathrm{ml}$ and $3.0(2.2-4.6) \mathrm{ng} / \mathrm{ml}$ versus 2.4 (1.7-3.5) $\mathrm{ng} / \mathrm{ml}$ for testosterone and androstenedione respectively). In age and BMI-adjusted analyses, the results were attenuated $(P=0.052$ and $P=0.087$ for testosterone and androstenedione respectively). After further adjustment for $25(\mathrm{OH}) \mathrm{D}$, calcium, and month of blood sampling, the $P$ values were 0.128 and 0.150 for testosterone and androstenedione respectively.

We did not observe an association of Apa-I polymorphism with metabolic parameters or 25(OH)D levels.

\section{VDR Bsm-I, Fok-I, and Taq-I}

There was no association of VDR Bsm-I, Fok-I, and Taq-I polymorphisms with anthropometric, endocrine, or metabolic parameters.

\section{GC}

We observed a significant association of GC polymorphism with $25(\mathrm{OH}) \mathrm{D}$ levels in crude (Fig. 1a) as well as in multivariate-adjusted (age and month of blood sampling; $P=0.049$ ) analyses. PCOS women carrying the GG genotype had significantly higher risk for vitamin D deficiency than women carrying the TT genotype in crude (OR 2.98 (1.54-5.77), $P=0.001$ ) as well as in multivariate-adjusted analyses (Fig. 1c). In binary logistic regression analyses calculating ORs for combined vitamin D insufficiency and deficiency $(25(\mathrm{OH}) \mathrm{D}$ levels $<30 \mathrm{ng} / \mathrm{ml})$, we found a significant higher risk in PCOS women carrying the $G G$ allele compared with TT carriers in the crude model (OR 2.47 (1.12-5.47); $P=0.026)$ as well as in the multivariate analysis adjusting for age, BMI, and month of blood sampling (OR 2.36 (1.03-5.39); $P=0.042)$.

Moreover, the weight, height, BMI, WC, TC, HDL, QChol/HDL, and AUCins levels were significantly different within GC genotypes (Table 2). The association of GC polymorphism with weight, height, WC, TC, HDL, and QChol/HDL remained significant in multivariateadjusted analyses (age, BMI, 25(OH)D, month of blood sampling, and serum calcium).
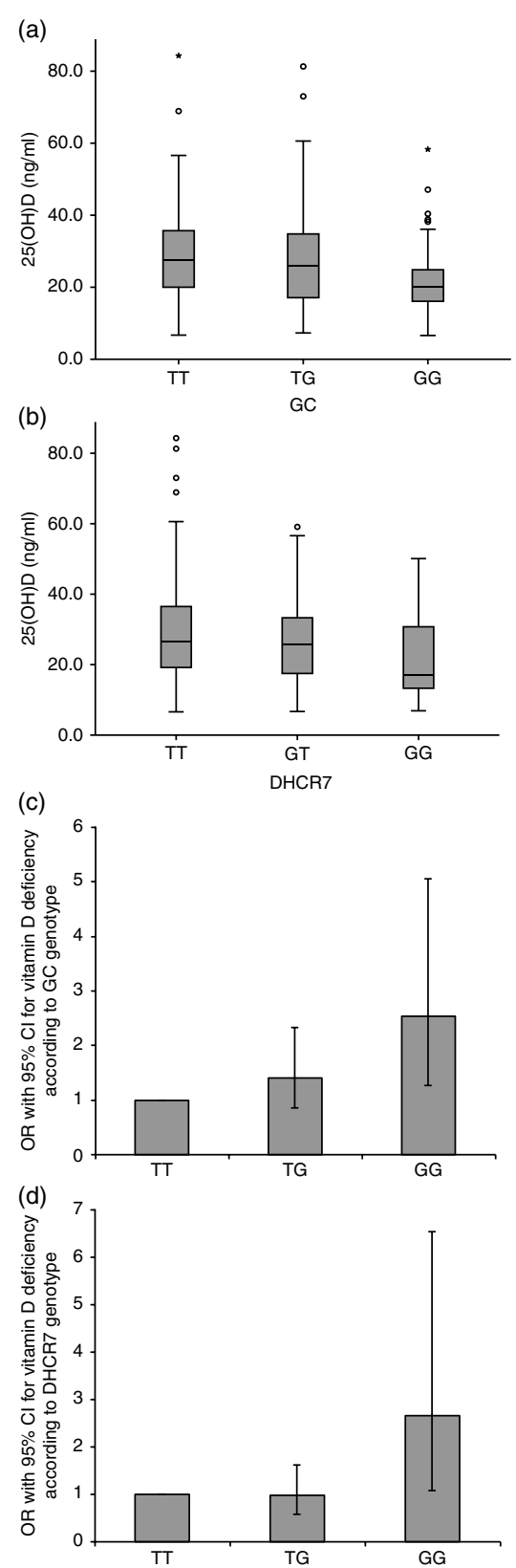

Figure $125(\mathrm{OH}) \mathrm{D}$ levels and ORs for vitamin $\mathrm{D}$ deficiency ( $<20 \mathrm{ng} / \mathrm{ml}$ ) according to $G C$ and $D H C R 7$ genotypes in PCOS women. (a) 25(OH)D levels in PCOS women according to GC polymorphism (27.6 (20.0-35.7) $\mathrm{ng} / \mathrm{ml}$ in TT, $25.9(17.1-34.8)$ $\mathrm{ng} / \mathrm{ml}$ in TG, and $20.1(16.1-25.6) \mathrm{ng} / \mathrm{ml}$ in GG carriers; $P=0.027$ for TT versus $\mathrm{GG}$ ). To convert $25(\mathrm{OH}) \mathrm{D}$ levels into $\mathrm{nM} / \mathrm{l}$, multiply by 2.496. (b) $25(\mathrm{OH}) \mathrm{D}$ levels in PCOS women according to DHCR7 polymorphism (26.5 (19.2-36.5) $\mathrm{ng} / \mathrm{ml}$ in TT, 25.7 (17.5-33.3) $\mathrm{ng} / \mathrm{ml}$ in TG, and $17.1(13.3-30.8) \mathrm{ng} / \mathrm{ml}$ in GG carriers; $P=0.006$ for TT versus $\mathrm{GG}$ ). To convert 25(OH)D levels into $\mathrm{nM} / \mathrm{l}$, multiply by 2.496. (c) ORs for vitamin D deficiency $(<20 \mathrm{ng} / \mathrm{ml})$ according to GC genotype (TT reference). OR 2.53 (1.27-5.06), $P=0.009$, adjusted for age, BMI, and month of blood sampling. (d) ORs for vitamin $D$ deficiency $(<20 \mathrm{ng} / \mathrm{ml})$ according to $D H C R 7$ genotype (TT reference). OR 2.66 (1.08-6.55), $P=0.033$, adjusted for age, $\mathrm{BMI}$, and month of blood sampling. 


\section{DHCR7}

We found a significant association of DHCR7 variants with 25(OH)D levels in crude (Fig. 1b) as well as in multivariate-adjusted analyses (adjusted for age, BMI, and month of blood sampling, $P=0.035$ ). In binary logistic regression analyses, PCOS women carrying the GG genotype had significantly higher risk for vitamin D deficiency than women carrying the TT genotype in crude (OR $3.27(1.45-7.39), P=0.004$ ) as well as in multivariate-adjusted analyses (Fig. 1d). In binary logistic regression analyses calculating ORs for combined vitamin D insufficiency and deficiency $(25(\mathrm{OH}) \mathrm{D}$ levels $<30 \mathrm{ng} / \mathrm{ml}$ ), we found no significant association with DHCR 7 genotype.

Moreover, the hip circumference, fasting glucose, glucose $2 \mathrm{~h}$, fasting insulin, insulin $2 \mathrm{~h}$, TC, TG, HOMAIR, MATSUDA, QUICKI, and serum phosphate levels were significantly different within DHCR7 genotypes (Table 2).

In multivariate-adjusted analyses (age, BMI, month of blood sampling, serum calcium, and 25(OH)D), the association of DHCR7 with $2 \mathrm{~h}$ insulin and TC remained significant, whereas the other association lost significance.

\section{CYP2R1}

The 25(OH)D levels were similar within the genotypes (28.1 (20.0-39.4) ng/ml, 25.2 (18.3-32.2) ng/ml, and $25.2(17.4-34.6)$ for AA, AG, and GG respectively, $P=0.412$ ). In binary logistic regression analyses, we observed a trend toward an increased risk for vitamin D deficiency in PCOS women carrying the GG genotype compared with PCOS women carrying the AA genotype in multivariate-adjusted analyses (OR 2.18 $(0.97-4.92), P=0.059)$. In binary logistic regression analyses calculating ORs for combined vitamin D insufficiency and deficiency $(25(\mathrm{OH}) \mathrm{D}$ levels $<30 \mathrm{ng} / \mathrm{ml}$ ), we found no significant association with CYP2R 1 genotype.

We found a significant association of the CYP2R 1 polymorphism with $30 \mathrm{~min}$ glucose and AUC glucose levels $(P<0.005$ for both).

\section{Combined analyses}

We performed additional analyses to assess the combined effect of the three variants influencing the risk for vitamin D deficiency (GC, DHCR7, and CYP2R1). As only one women presented with all the three risk genotypes, we combined PCOS women with two $(8.3 \%$ of all women) and three risk genotypes. ORs for vitamin $\mathrm{D}$ deficiency were 1.68 $(1.01-2.81) \quad(P=0.047)$ and $2.66 \quad(1.12-6.32)$ $(P=0.026)$ for $\mathrm{PCOS}$ women carrying 1 or $\geq 2$ risk genotypes respectively.

\section{Discussion}

We present evidence that VDR and vitamin D levelrelated genetic variants are associated with metabolic and endocrine parameters including 25(OH)D levels in PCOS women. In detail, variants in the VDR $C d x 2$ and DHCR7 genes are associated with IR and insulin sensitivity and VDR Apa-I variants are associated with testosterone levels in PCOS women. We did not observe any association of vitamin D-related polymorphisms and PCOS susceptibility. However, we found an independent association of GC and DHCR 7 polymorphisms with vitamin D deficiency in PCOS women.

Polymorphisms of the VDR gene might be associated with PCOS and biochemical markers related to PCOS $(11,12)$. These studies involved the analyses of variants that are located at the $3^{\prime}$-end of the VDR gene such as the VDR Bsm-I, Apa-I, and Taq-I. However, those variants are not likely to influence the function of the VDR itself because they are in an intron or do not change amino acid sequence (18). In contrast, CDX2 acts as a transcription factor of VDR (19) and VDR regulates the transcription of about 3\% of the human genome (9). Yamamoto et al. (20) first described a functional binding site for the intestinal-specific transcription factor CDX2 in the 1a promoter region of the VDR gene. The $\mathrm{G}$ to A substitution, which was investigated in our study, was first described by Arai et al. (19) and was found to modulate the intestinespecific transcription of the VDR gene. The CDX2 protein binds more specifically to the $A$-allele and leads to increased transcription of the $V D R$ gene. Of note, the VDR itself is a transcription factor and regulates the transcription of other downstream genes in many tissues including genes that are crucial for glucose metabolism $(9,10)$.

Whereas the VDR $C d x 2$ polymorphism has been shown to be associated with BMD and fracture risk (18), the association with metabolic parameters has not been investigated so far. It can be hypothesized that VDR $C d x 2 A$-allele carriers have higher intestinal calcium absorption, because of the elevated expression of intestinal calcium channel proteins (21). Calcium fluxes and regulation of intracellular calcium stores are essential in the regulation of insulin secretion by the $\beta$-cells. This makes vitamin $\mathrm{D}$, the central hormone in calcium regulation, as well VDR genes a candidate for influencing $\beta$-cell function. This notion is further supported by the fact that low vitamin D levels are associated with IR and type 2 diabetes in PCOS $(6,7)$ as well as in other cohorts (10). The exact mechanisms underlying the association of vitamin D and IR are not fully understood. First, vitamin D may have a beneficial effect on insulin action by stimulating the expression of insulin receptor and thereby enhancing insulin responsiveness for glucose transport (10). The vitamin D-responsive element is present in the promoter of the human insulin gene (22) and the transcription of the 
human insulin gene is activated by 1,25(OH)D2 (23). Secondly, vitamin D regulates extracellular and intracellular calcium that is essential for insulin-mediated intracellular processes in insulin-responsive tissues such as skeletal muscle and adipose tissue (10). Moreover, alterations in calcium flux can have adverse effects on insulin secretion, which is a calciumdependent process (24). Finally, as vitamin D has a modulating effect on the immune system (25), hypovitaminosis D might induce a higher inflammatory response, which is again associated with IR (26).

Interestingly, Mahmoudi et al. (11) report an association of VDR Apa-I polymorphism with PCOS status in a small cohort. In our cohort, no association was found with PCOS susceptibility. In particular, we observed an association of VDR Apa-I with androgen levels in crude analyses. However, these association lost significance in multivariate-adjusted analyses including 25(OH)D. Previously, we demonstrated a BMI-independent association of 25(OH)D levels with hirsutism score (7) and others (6) showed an association of 25(OH)D and FAI levels in PCOS. Of note, 25(OH)D levels are correlated with androgen levels in men and display a similar seasonal variation (27). Thus, one might speculate on an association of vitamin D with androgens. The underlying mechanisms, however, remain to be explored.

Low 25(OH)D levels have been linked to increased risk for cancer (28), autoimmune disease, diabetes (9), cardiovascular disease (29), and increased mortality (30), indicating the importance of sufficient $25(\mathrm{OH}) \mathrm{D}$ levels. Although there is no consensus on optimal levels of $25(\mathrm{OH}) \mathrm{D}$, a level of $20 \mathrm{ng} / \mathrm{ml}$ has been suggested to cover the requirements of at least $97.5 \%$ of the population according to the latest public health report (31). Others (32), however, consider a $25(\mathrm{OH}) \mathrm{D}$ level of $30-44 \mathrm{ng} / \mathrm{ml}$ sufficient. In our study, only $34.1 \%$ of PCOS women present with 25(OH)D levels $>30 \mathrm{ng} / \mathrm{ml}$ and $68.8 \%$ with $25(\mathrm{OH}) \mathrm{D}$ levels $>20 \mathrm{ng} / \mathrm{ml}$. In line with the genome-wide association study (13), we observed a strong independent association of GC ' $\mathrm{GG}$ ' and DHCR7 'GG' genotype with risk for vitamin D deficiency. The detection of those alleles might assist in the identification of a subgroup of patients who are at an especially high risk for vitamin D deficiency. Of note, interindividual differences have been reported in response to treatment with identical doses of vitamin D (33). Thus, further studies investigating whether genetic predisposition modifies the response to sun exposure or dietary supplementation are warranted especially in these high-risk PCOS women, who are frequently affected by obesity and metabolic disturbances. Identification of genetic association patterns might pave the way to a more personalized approach to therapy.

The GC gene encodes a multifunctional plasma protein GC, also known as a group-specific component, or vitamin D binding protein (VDBP), a protein that is synthesized in the liver that binds and transports vitamin $\mathrm{D}$ and its metabolites. Apart from its specific sterol binding capacity, VDBP exerts several other important biological functions such as actin scavenging, fatty acid transport, macrophage activation, and chemotaxis (34). We observed an independent association of GC polymorphism with lipids in our PCOS cohort. Of note, a major function of VDBP is the binding of mainly monounsaturated and saturated fatty acids (34). Moreover, we observed an association of GC polymorphism with anthropometric measures that was independent of $25(\mathrm{OH}) \mathrm{D}$ levels. The link of obesity with vitamin D has been described in PCOS (7) as well as in other cohorts (35), the relationship with VDBP is, however, less clear. Taes et al. (2006) (36) described a positive relationship between VDBP concentrations and BMI in a cohort of elderly men. Overall, the underlying mechanisms of this association are not known so far but deserve further investigation.

DHCR7 encodes the enzyme 7-dehydrocholesterol (7-DHC) reductase, which converts 7-DHC to cholesterol. 7-DHC reductase removes 7-DHC, which is a precursor of $25(\mathrm{OH}) \mathrm{D}$, from the synthetic pathway of vitamin D3. Rare mutations in DHCR7 lead to SmithLemli-Opitz syndrome. People affected by the syndrome present with reduced activity of 7-DHC reductase, accumulation of 7-DHC, low cholesterol, and many congenital abnormalities (37). In our study, we found an association of DHCR7 polymorphism with 25(OH)D levels as well as metabolic parameters including glucose, insulin, and lipids. Most of these associations were attenuated in multivariate analyses, which indicates that they are most likely mediated via $25(\mathrm{OH}) \mathrm{D}$ levels underlining again the important association of vitamin D with IR and action. Nevertheless, those polymorphisms might be important in risk prediction or risk calculation in PCOS women. One might also speculate that vitamin D supplementation is of especially high importance in certain vitamin Ddeficient women with the GG genotype of DHCR7.

CYP2R 1 encodes a hepatic microsomal enzyme that might be the enzyme responsible for the 25-hydroxylation in the liver. However, many other enzymes with 25-hydroxylase activity have been described (38). Whereas the results from the large genome-wide association study (13) demonstrated a strong association of CYP2R1 with 25(OH)D levels, we observed a trend without a significant association.

One limitation of our study is the relatively small sample size of our control group, which might limit the power to detect differences in genotype distribution of PCOS and control women. Moreover, we did not measure serum levels of VDBP. Thus, our analyses are restricted to the GC polymorphism and cannot be extended to circulating VDBP concentrations, which might have allowed further insights into the association of GC polymorphism with anthropometric and biochemical parameters. The strength of this study is the 
number and precise metabolic characterization of PCOS women by oral glucose tolerance tests.

In summary, variants in the VDR $C d x 2$ and DHCR7 genes are associated with IR and insulin sensitivity and VDR Apa-I variants are associated with testosterone levels in PCOS women. Moreover, we confirmed the results from previous genome-wide association studies showing an association of GC and DHCR7 polymorphisms with an increased risk for vitamin D deficiency. Further studies investigating whether genetic predisposition modifies response to vitamin D supplementation are warranted.

\section{Declaration of interest}

The authors declare that there is no conflict of interest that could be perceived as prejudicing the impartiality of the research reported.

\section{Funding}

This research did not receive any specific grant from any funding agency in the public, commercial, or not-for-profit sector.

\section{Acknowledgements}

We thank Antonia Griesbacher, MSc, for her statistical support.

\section{References}

1 Asunción M, Calvo RM, San Millán JL, Sancho J, Avila S \& EscobarMorreale HF. A prospective study of the prevalence of the polycystic ovary syndrome in unselected Caucasian women from Spain. Journal of Clinical Endocrinology and Metabolism $2000 \mathbf{8 5}$ 2434-2438. (doi:10.1210/jc.85.7.2434)

2 Diamanti-Kandarakis E, Kouli CR, Bergiele AT, Filandra FA, Tsianateli TC, Spina GG, Zapanti ED \& Bartzis MI. A survey of the polycystic ovary syndrome in the Greek island of Lesbos: hormonal and metabolic profile. Journal of Clinical Endocrinology and Metabolism $1999 \mathbf{8 4}$ 4006-4011. (doi:10.1210/jc.84.11. 4006)

3 Dunaif A. Insulin resistance and the polycystic ovary syndrome: mechanism and implications for pathogenesis. Endocrine Reviews 199718 774-800. (doi:10.1210/er.18.6.774)

4 Wehr E, Möller R, Horejsi R, Giuliani A, Kopera D, Schweighofer N, Groselj-Strele A, Pieber TR \& Obermayer-Pietsch B. Subcutaneous adipose tissue topography and metabolic disturbances in polycystic ovary syndrome. Wiener Klinische Wochenschrift 2009121 262-269. (doi:10.1007/s00508-009-1162-2)

5 Ehrmann DA. Polycystic ovary syndrome. New England Journal of Medicine 2005352 1223-1236. (doi:10.1056/NEJMra041536)

6 Hahn S, Haselhorst U, Tan S, Quadbeck B, Schmidt M, Roesler S, Kimmig R, Mann K \& Janssen OE. Low serum 25-hydroxyvitamin $\mathrm{D}$ concentrations are associated with insulin resistance and obesity in women with polycystic ovary syndrome. Experimental and Clinical Endocrinology and Diabetes 2006114 577-583. (doi:10.1055/s-2006-948308)

7 Wehr E, Pilz S, Schweighofer N, Giuliani A, Kopera D, Pieber T \& Obermayer-Pietsch B. Association of hypovitaminosis D with metabolic disturbances in polycystic ovary syndrome. European Journal of Endocrinology 2009161 575-582. (doi:10.1530/EJE09-0432)
8 Wehr E, Pieber TR \& Obermayer-Pietsch B. Effect of vitamin D3 treatment on glucose metabolism and menstrual frequency in PCOS women - a pilot study. Journal of Endocrinological Investigation, 2010 In press.

9 Holick MF. Vitamin D deficiency. New England Journal of Medicine 2007357 266-281. (doi:10.1056/NEJMra070553)

10 Pittas AG, Lau J, Hu FB \& Dawson-Hughes B. The role of vitamin D and calcium in type 2 diabetes. A systematic review and metaanalysis. Journal of Clinical Endocrinology and Metabolism 200792 2017-2029. (doi:10.1210/jc.2007-0298)

11 Mahmoudi T. Genetic variation in the vitamin D receptor and polycystic ovary syndrome risk. Fertility and Sterility 200992 1381-1383. (doi:10.1016/j.fertnstert.2009.05.002)

12 Ranjzad F, Mahban A, Irani Shemirani A, Mahmoudi T, Vahedi M, Nikzamir A \& Zali M. Influence of gene variants related to calcium homeostasis on biochemical parameters of women with polycystic ovary syndrome. Journal of Assisted Reproduction and Genetics, 2010 In press.

13 Wang TJ, Zhang F, Richards JB, Kestenbaum B, van Meurs JB, Berry D, Kiel DP, Streeten EA, Ohlsson C, Koller DL, Peltonen L, Cooper JD, O'Reilly PF, Houston DK, Glazer NL, Vandenput L, Peacock M, Shi J, Rivadeneira F, McCarthy MI, Anneli P, de Boer IH, Mangino M, Kato B, Smyth DJ, Booth SL, Jacques PF, Burke GL, Goodarzi M, Cheung CL, Wolf M, Rice K, Goltzman D, Hidiroglou N, Ladouceur M, Wareham NJ, Hocking LJ, Hart D, Arden NK, Cooper C, Malik S, Fraser WD, Hartikainen AL, Zhai G, Macdonald HM, Forouhi NG, Loos RJ, Reid DM, Hakim A, Dennison E, Liu Y, Power C, Stevens HE, Jaana L, Vasan RS, Soranzo N, Bojunga J, Psaty BM, Lorentzon M, Foroud T, Harris TB, Hofman A, Jansson JO, Cauley JA, Uitterlinden AG, Gibson Q, Järvelin MR, Karasik D, Siscovick DS, Econs MJ, Kritchevsky SB, Florez JC, Todd JA, Dupuis J, Hyppönen E \& Spector TD. Common genetic determinants of vitamin D insufficiency: a genome-wide association study. Lancet 2010 376 180-188. (doi:10.1016/S0140-6736(10)60588-0)

14 The Rotterdam ESHRE/ASRM-sponsored consensus workshop group. Revised 2003 consensus on diagnostic criteria and longterm health risks related to polycystic ovary syndrome (PCOS). Human Reproduction 200419 41-47. (doi:10.1093/humrep/ deh098)

15 Legro RS, Castracane VD \& Kauffman RP. Detecting insulin resistance in polycystic ovary syndrome: purposes and pitfalls. Obstetrical and Gynecological Survey 200459 141-154. (doi:10. 1097/01.0GX.0000109523.25076.E2)

16 Katz A, Nambi SS, Mather K, Baron AD, Follmann DA, Sullivan G \& Quon MJ. Quantitative insulin sensitivity check index: a simple, accurate method for assessing insulin sensitivity in humans. Journal of Clinical Endocrinology and Metabolism 2000 85 2402-2410. (doi:10.1210/jc.85.7.2402)

17 Matsuda M \& DeFronzo RA. Insulin sensitivity indices obtained from oral glucose tolerance testing: comparison with the euglycemic insulin clamp. Diabetes Care 199922 1462-1470. (doi:10.2337/diacare.22.9.1462)

18 Fang Y, van Meurs JB, Bergink AP, Hofman A, van Duijn CM, van Leeuwen JP, Pols HA \& Uitterlinden AG. Cdx-2 polymorphism in the promoter region of the human vitamin $\mathrm{D}$ receptor gene determines susceptibility to fracture in the elderly. Journal of Bone and Mineral Research 200318 1632-1641. (doi:10.1359/jbmr. 2003.18.9.1632)

19 Arai H, Miyamoto KI, Yoshida M, Yamamoto H, Taketani Y, Morita K, Kubota M, Yoshida S, Ikeda M, Watabe F, Kanemasa Y \& Takeda E. The polymorphism in the caudal-related homeodomain protein $\mathrm{Cdx}-2$ binding element in the human vitamin $\mathrm{D}$ receptor gene. Journal of Bone and Mineral Research 200116 1256-1264. (doi:10.1359/jbmr.2001.16.7.1256)

20 Yamamoto H, Miyamoto K, Li B, Taketani Y, Kitano M, Inoue Y, Morita K, Pike JW \& Takeda E. The caudal-related homeodomain protein $\mathrm{Cdx}-2$ regulates vitamin $\mathrm{D}$ receptor gene expression in the small intestine. Journal of Bone and Mineral Research 199914 240-247. (doi:10.1359/jbmr.1999.14.2.240) 
21 Van Cromphaut SJ, Dewerchin M, Hoenderop JG, Stockmans I, Van Herck E, Kato S, Bindels RJ, Collen D, Carmeliet P, Bouillon R \& Carmeliet G. Duodenal calcium absorption in vitamin D receptor-knockout mice: functional and molecular aspects. PNAS 200198 13324-13329. (doi:10.1073/pnas.231474698)

22 Maestro B, Dávila N, Carranza MC \& Calle C. Identification of a Vitamin D response element in the human insulin receptor gene promoter. Journal of Steroid Biochemistry and Molecular Biology 200384 223-230. (doi:10.1016/S0960-0760(03)00032-3)

23 Maestro B, Molero S, Bajo S, Dávila N \& Calle C. Transcriptional activation of the human insulin receptor gene by 1,25dihydroxyvitamin D(3). Cell Biochemistry and Function 200220 227-232. (doi:10.1002/cbf.951)

24 Milner RD \& Hales $\mathrm{CN}$. The role of calcium and magnesium in insulin secretion from rabbit pancreas studied in vitro. Diabetologia 19673 47-49. (doi:10.1007/BF01269910)

25 Bikle D. Nonclassic actions of vitamin D. Journal of Clinical Endocrinology and Metabolism 200994 26-34. (doi:10.1210/jc. 2008-1454)

26 Shoelson SE, Herrero L \& Naaz A. Obesity, inflammation, and insulin resistance. Gastroenterology 2007132 2169-2180. (doi:10.1053/j.gastro.2007.03.059)

27 Wehr E, Pilz S, Boehm BO, März W \& Obermayer-Pietsch B. Association of vitamin D status with serum androgen levels in men. Clinical Endocrinology 201073 243-248. (doi:10.1111/j. 1365-2265.2010.03852.x)

28 Pilz S, Dobnig H, Winklhofer-Roob B, Riedmüller G, Fischer JE, Seelhorst U, Wellnitz B, Boehm BO \& März W. Low serum levels of 25-hydroxyvitamin D predict fatal cancer in patients referred to coronary angiography. Cancer Epidemiology, Biomarkers and Prevention 200817 1228-1233. (doi:10.1158/1055-9965.EPI08-0002)

29 Pilz S, März W, Wellnitz B, Seelhorst U, Fahrleitner-Pammer A, Dimai HP, Boehm BO \& Dobnig H. Association of vitamin D deficiency with heart failure and sudden cardiac death in a large cross-sectional study of patients referred for coronary angiography. Journal of Clinical Endocrinology and Metabolism 200893 3927-3935. (doi:10.1210/jc.2008-0784)

30 Melamed ML, Michos ED, Post W \& Astor B. 25-Hydroxyvitamin D levels and the risk of mortality in the general population. Archives of Internal Medicine $2008 \mathbf{1 6 8}$ 1629-1637. (doi:10.1001/ archinte.168.15.1629)

31 Ross AC, Manson JE, Abrams SA, Aloia JF, Brannon PM, Clinton SK, Durazo-Arvizu RA, Gallagher JC, Gallo RL, Jones G, Kovacs CS, Mayne ST, Rosen CJ \& Shapses SA. The 2011 report on dietary reference intakes for calcium and vitamin D from the Institute of Medicine: what clinicians need to know. Journal of Clinical Endocrinology and Metabolism 201096 53-58. (doi:10. 1210/jc.2010-2704)

32 Souberbielle JC, Body JJ, Lappe JM, Plebani M, Shoenfeld Y, Wang TJ, Bischoff-Ferrari HA, Cavalier E, Ebeling PR, Fardellone P, Gandini S, Gruson D, Guérin AP, Heickendorff L, Hollis BW, IshShalom S, Jean G, von Landenberg P, Largura A, Olsson T, PierrotDeseilligny C, Pilz S, Tincani A, Valcour A \& Zittermann A. Vitamin D and musculoskeletal health, cardiovascular disease, autoimmunity and cancer: recommendations for clinical practice. Autoimmunity Reviews 20109 709-715. (doi:10.1016/j.autrev. 2010.06.009)

33 Elnenaei MO, Chandra R, Mangion T \& Moniz C. Genomic and metabolomic patterns segregate with responses to calcium and vitamin D supplementation. British Journal of Nutrition 2010105 $71-79$.

34 Speeckaert M, Huang G, Delanghe JR \& Taes YE. Biological and clinical aspects of the vitamin D binding protein (Gc-globulin) and its polymorphism. Clinica Chimica Acta; International Journal of Clinical Chemistry 2006372 33-42. (doi:10.1016/j.cca.2006.03. 011)

35 Arunabh S, Pollack S, Yeh J \& Aloia JF. Body fat content and 25-hydroxyvitamin D levels in healthy women. Journal of Clinical Endocrinology and Metabolism 200388 157-161. (doi:10.1210/ jc.2002-020978)

36 Taes YE, Goemaere S, Huang G, Van Pottelbergh I, De Bacquer D, Verhasselt B, Van den Broeke C, Delanghe JR \& Kaufman JM. Vitamin D binding protein, bone status and body composition in community-dwelling elderly men. Bone $2006 \mathbf{3 8}$ 701-707. (doi:10.1016/j.bone.2005.10.006)

37 Tint GS, Irons M, Elias ER, Batta AK, Frieden R, Chen TS \& Salen G. Defective cholesterol biosynthesis associated with the SmithLemli-Opitz syndrome. New England Journal of Medicine 1994330 107-113. (doi:10.1056/NEJM199401133300205)

38 Cheng JB, Levine MA, Bell NH, Mangelsdorf DJ \& Russell DW. Genetic evidence that the human CYP2R1 enzyme is a key vitamin D 25-hydroxylase. PNAS 2004101 7711-7715. (doi:10. 1073/pnas.0402490101)

Received 7 March 2011

Accepted 9 March 2011 